\title{
Remifentanil versus dexmedetomidine for treatment of cardiac surgery patients with moderate to severe noninvasive ventilation intolerance (REDNIVIN): a prospective, cohort study
}

\author{
Guang-Wei Hao ${ }^{1 \#}$, Jing-Chao Luo ${ }^{1 \#}$, Yan Xue ${ }^{2 \#}$, Guo-Guang Ma ${ }^{1}$, Ying $\mathrm{Su}^{1}$, Jun-Yi Hou ${ }^{1}$, Shen-Ji Yu ${ }^{1}$, \\ Kai Liu ${ }^{1}$, Ji-Li Zheng ${ }^{2}$, Guo-Wei Tu ${ }^{1}$, Zhe Luo ${ }^{1,3}$ \\ ${ }^{1}$ Department of Critical Care Medicine, Zhongshan Hospital, Fudan University, Shanghai, China; ${ }^{2}$ Department of Nursing, Zhongshan Hospital, \\ Fudan University, Shanghai, China; ${ }^{3}$ Department of Critical Care Medicine, Xiamen Branch, Zhongshan Hospital Fudan University, Xiamen, China \\ Contributions: (I) Conception and design: GW Hao, JC Luo, Y Xue, GW Tu, Z Luo; (II) Administrative support: None; (III) Provision of study \\ material or patients: GW Hao, JC Luo, Y Xue, GG Ma, Y Su, JY Hou; (IV) Collection and assembly of data: SJ Yu, K Liu, JL Zheng; (V) Data \\ analysis and interpretation: GW Hao, JC Luo, Y Xue; (VI) Manuscript writing: All authors; (VII) Final approval of manuscript: All authors. \\ \#These authors contributed equally to this work. \\ Correspondence to: Zhe Luo. Department of Critical Care Medicine, Zhongshan Hospital, Fudan University, Shanghai 200032, China; Department of \\ Critical Care Medicine, Xiamen Branch, Zhongshan hospital, Fudan University, Xiamen 361015, China. Email: luo.zhe@zs-hospital.sh.cn; Guo-Wei \\ Tu. Department of Critical Care Medicine, Zhongshan Hospital, Fudan University, Shanghai 200032, China. Email: tu.guowei@zs-hospital.sh.cn.
}

Background: The use of sedation to noninvasive ventilation (NIV) patients remains controversial, however, for intolerant patients who are uncooperative, administration of analgesics and sedatives may be beneficial before resorting to intubation. The aim of this study was to evaluate the efficacy of remifentanil (REM) versus dexmedetomidine (DEX) for treatment of cardiac surgery (CS) patients with moderate to severe NIV intolerance.

Methods: This prospective cohort study of CS patients with moderate to severe NIV intolerance was conducted between January 2018 and March 2019. Patients were treated with either REM or DEX, decided by the bedside intensivist. Depending on the treatment regimen, the patients were allocated to one of two groups: the REM group or DEX group.

Results: A total of 90 patients were enrolled in this study (52 in the REM group and 38 in the DEX group). The mitigation rate, defined as the percentage of patients who were relieved from the initial moderate to severe intolerant status, was greater in the REM group than DEX group at $15 \mathrm{~min}$ and $3 \mathrm{~h}(15 \mathrm{~min}: 83 \%$ vs. $61 \%, \mathrm{P}=0.029 ; 3$ h: $92 \%$ vs. $74 \%, \mathrm{P}=0.016)$, although the mean mitigation rate $(81 \%$ vs. $85 \%, \mathrm{P}=0.800)$ was comparable between the two groups. NIV failure, defined as reintubation or death over the course of study, was comparable between the two groups ( $19.2 \%$ vs. $21.1 \%$, respectively, $\mathrm{P}=0.831)$. There were no significant differences between the two groups in other clinical outcomes, including tracheostomy $(15.4 \% v s$. $15.8 \%, \mathrm{P}=0.958)$, in-hospital mortality (11.5\% vs. $10.5 \%, \mathrm{P}=0.880)$, ICU length of stay (LOS) (7 vs. 7 days, $\mathrm{P}=0.802)$, and in-hospital LOS (17 vs. 19 days, $\mathrm{P}=0.589)$.

Conclusions: REM was as effective as DEX in CS patients with moderate to severe NIV intolerance. Although the effect of REM was better than that of DEX over the first $3 \mathrm{~h}$, the cumulative effect was similar between the two treatments.

Keywords: Remifentanil; dexmedetomidine; non-invasive ventilation; cardiac surgery

Submitted Apr 17, 2020. Accepted for publication Aug 19, 2020.

doi: $10.21037 /$ jtd-20-1678

View this article at: http://dx.doi.org/10.21037/jtd-20-1678 


\section{Introduction}

Noninvasive ventilation (NIV) after cardiac surgery (CS) has been broadly applied in recent years (1-3). However, NIV is unsuccessful in about $40 \%$ to $50 \%$ of patients undergoing CS $(2,4)$. Although great efforts have been made to improve patient-ventilator synchrony, NIV intolerance is one of the main causes of NIV failure (5-7).

Studies have shown that procedural sedation and analgesia as a salvage strategy are both safe and effective for patients intolerant to NIV (8-11). However, to date, there is no consensus on sedation protocols for such patients (12). Dexmedetomidine (DEX) is a potent, highly selective, $\alpha 2$-adrenergic agonist with intrinsic analgesic properties as well as sedative, anxiolytic, and sympatholytic effects $(13,14)$. The usefulness of DEX for sedation in the intensive care unit (ICU) setting has been widely reported (15-17), including the cardiac surgery ICU (CSICU) $(18,19)$. However, DEX is associated with high incidences of bradycardia and hypotension (20-22). Opioids, which are commonly used in the ICU setting, have a protective function on heart tissue and, thus, are often included in the treatment regimens for various cardiovascular diseases, including congestive heart failure, ischemic heart disease, hypertension, arrhythmia, and hyperlipidemia (23). Remifentanil (REM) is an ultra-short-acting opioid with $\mu$-selectivity with an onset of action of less than $1 \mathrm{~min}$ that quickly achieves a steady state (24). The elimination half-life of REM is less than $10 \mathrm{~min}$, independent of renal function, hepatic function, and infusion duration $(25,26)$. Based on these characteristics, REM is a very attractive option for NIV intolerance in CS patients.

In our center, DEX used to be the drug of choice for NIV intolerance. However, in June 2017, REM was introduced and was soon widely used for the treatment of patients by both invasive and noninvasive mechanical ventilation. Since then, patients with NIV intolerance were treated via either REM or DEX, decided by the bedside intensivist. And we wanted to know whether REM was as effective as DEX for CS patients intolerant to NIV. Therefore, this prospective, cohort study was designed to evaluate the efficacy of REM versus DEX for treatment of CS patients with NIV intolerance.

We present the following article in accordance with the Strengthening the Reporting of Observational Studies in Epidemiology (STROBE) reporting checklist (available at http://dx.doi.org/10.21037/jtd-20-1678).

\section{Methods}

\section{Setting}

This single center, prospective, cohort study was conducted in a 39-bed CSICU at Zhongshan Hospital from January 2018 to March 2019. This hospital is one of the largest cardiovascular surgery centers in mainland China, which performs more than 4500 cardiac procedures every year. The study was conducted in accordance with the Declaration of Helsinki (as revised in 2013). The Ethical Committee of Zhongshan hospital, Fudan University approved this study (NO. B2017-187). Informed consent was acquired from each patient's relatives, after the potential risks and purpose of this study were explained and understood. This study was registered on ClinicalTrials.gov (NCT03395886).

\section{Population}

All adult CS patients who received NIV and developed moderate to severe intolerance between January 2018 and March 2019 in our CSICU were enrolled in this study. Tolerance to NIV was evaluated using a four-point NIV intolerance score (NIS), which has been validated in NIVintolerant patients $(27,28)$. A score of 1 indicated a tolerant patient who felt comfortable and relaxed with NIV; a score of 2 indicated a mildly intolerant patient who felt some degree of discomfort and occasionally grabbed at the NIV mask; a score of 3 indicated a moderate intolerant patient who felt discomfort with the NIV mask most of the time and frequently grabbed at the mask (sometimes pulled it off); and a score of 4 indicated a severe intolerant patient who was agitated and/or unable to leave the NIV mask in place. The exclusion criteria were as follows: (I) difficult expectoration; (II) pregnancy/breastfeeding; and (III) severe hemodynamic instability defined by mean arterial pressure of $<60 \mathrm{mmHg}$ despite fluid optimization and administration of vasoactive drugs.

\section{NIV support}

NIV was performed via a facial mask (ZS-MZ-A; Shanghai Zhongshan Medical Technology, Shanghai, China) connected to a Dräger ventilator (Drägerwerk AG, Lubeck, Germany) in pressure support mode. NIV was started with fractional inspired oxygen concentration of $100 \%$, level of pressure support of $12 \mathrm{cmH}_{2} \mathrm{O}$ and positive end expiratory 
pressure of $5 \mathrm{cmH}_{2} \mathrm{O}$. The ventilator settings were then titrated according to the patient's vital signs, tolerance, and/ or arterial blood gas analysis.

In this study, NIV support was triggered by a comprehensive assessment, following American Thoracic Society guideline (2017) (29). And the criteria for NIV support in our center were as follows: (I) hypoxemia with a partial pressure of oxygen/fraction of inspired oxygen $\left(\mathrm{PaO}_{2} /\right.$ $\mathrm{FiO}_{2}$ ) ratio of $<150 \mathrm{mmHg}$; (II) tachypnea with a respiratory rate (RR) of $>25$ breaths/min for at least $2 \mathrm{~h}$; (III) signs of increased work of breathing, use of accessory respiratory muscles, and/or paradoxical abdominal movement; and (IV) sequential NIV after extubation for high-risk patients.

In this study, if the level of pressure support applied was titrated to $5 \mathrm{cmH}_{2} \mathrm{O}$ for more than 2 hours, the patients would be weaned by removing the facial mask and breathing spontaneously with oxygen supplementation. NIV was resumed without delay once one or more of the following developed: (I) peripheral capillary oxygen saturation $\left(\mathrm{SpO}_{2}\right)$ $<94 \%$; (II) $\mathrm{RR} \geq 25$ breaths/min; and/or (III) signs of increased work of breathing, use of accessory respiratory muscles, and/or paradoxical abdominal movement.

The criteria for reintubation in this study were: (I) patient's refusal to continue NIV due to persistent intolerance; (II) clinical signs of respiratory failure despite maximum NIV support; (III) the development of conditions requiring airway protection, such as coma, seizure, and copious tracheal secretions, etc.; (IV) severe hemodynamic instability; and (V) life-threatening arrhythmia.

\section{Treatment for NIV intolerance}

In this study, treatment for NIV intolerance was initiated when a NIS of 3 or 4 was recorded. The drug of choice was decided by the bedside intensivist, according to the patient's clinical status. Depending on the treatment regimen applied, the enrolled patients were allocated to one of two groups: the REM group or DEX group. The initial dosages of REM and DEX were $0.05 \mu \mathrm{g} / \mathrm{kg} / \mathrm{min}$ and $0.5 \mu \mathrm{g} / \mathrm{kg} / \mathrm{h}$, respectively. The dosages were then adjusted according to the treatment satisfaction (treatment target is to achieve NIS 1-2), with maximum dosages of REM and DEX of $0.12 \mu \mathrm{g} / \mathrm{kg} / \mathrm{min}$ and $1.0 \mu \mathrm{g} / \mathrm{kg} / \mathrm{h}$, respectively. If the NIS was still $\geq 3$ with the maximum dose of REM or DEX, midazolam or olanzapine were applied as needed. The level of sedation was evaluated using the Richmond Agitation and Sedation Scale (RASS), with an RASS score $\leq-4$ representing deep sedation (30).

\section{Data collection}

NIV-related data were obtained from an ongoing database started in January 2018, which was constructed prospectively and mainly focused on NIV-related parameters, such as level of pressure support, $\mathrm{FiO}_{2}$, tidal volume, NIS, RASS score, medication dosage, and vital signs (heart rate, $\mathrm{RR}$, blood pressure, $\mathrm{SPO}_{2}$ ). In this study, NIV-related parameters were collected at baseline, after $15 \mathrm{~min}$, after $1,3,6$, and $12 \mathrm{~h}$ of treatment, and every 12 $\mathrm{h}$ thereafter until NIV was discontinued or $72 \mathrm{~h}$ after the initiation of treatment. Demographic and clinical data were collected from an electronic medical record system.

\section{Outcomes measures}

In this study, the status of patients after the initiation of treatment was categorized as NIV failure, NIV intolerance, NIV tolerance, or NIV liberation. NIV failure was defined as reintubation or death within $72 \mathrm{~h}$, NIV intolerance as NIS of 3 or 4 , NIV tolerance as NIS of 1 or 2, and NIV liberation as no mechanical ventilation support. Mitigation was defined as relief from initial moderate to severe NIV intolerance. Reasons for NIV were categorized as cardiac or noncardiac, according to the patients' clinical manifestations and bedside examinations, such as chest $\mathrm{X}$-ray, point of care ultrasound, etc.

The primary outcome of this study was mitigation from NIV intolerance, including mitigation rates at different time points and the 72-h mean mitigation rate. The secondary outcome was NIV failure between the two groups.

\section{Statistical analyses}

Summary statistics are expressed as the mean \pm standard deviation, the median and interquartile ranges (25th to 75 th percentile), or number and percentage. Continuous variables were compared using the Student's $t$-test or the Mann-Whitney $U$ test as appropriate, while categorical variables were compared using the Chi-Square test or Fisher's exact test when necessary. And normality of variables was assessed by the Kolmogorov-Smirnov test, as needed. A percentage stacked area chart of patient status was constructed after administration of both drugs. The generalized estimating equations approach was employed to analyze changes in the mitigation rate over time between the two groups. All statistical tests were two-tailed and a probability $(\mathrm{P})$ value of $<0.05$ was considered statistically 


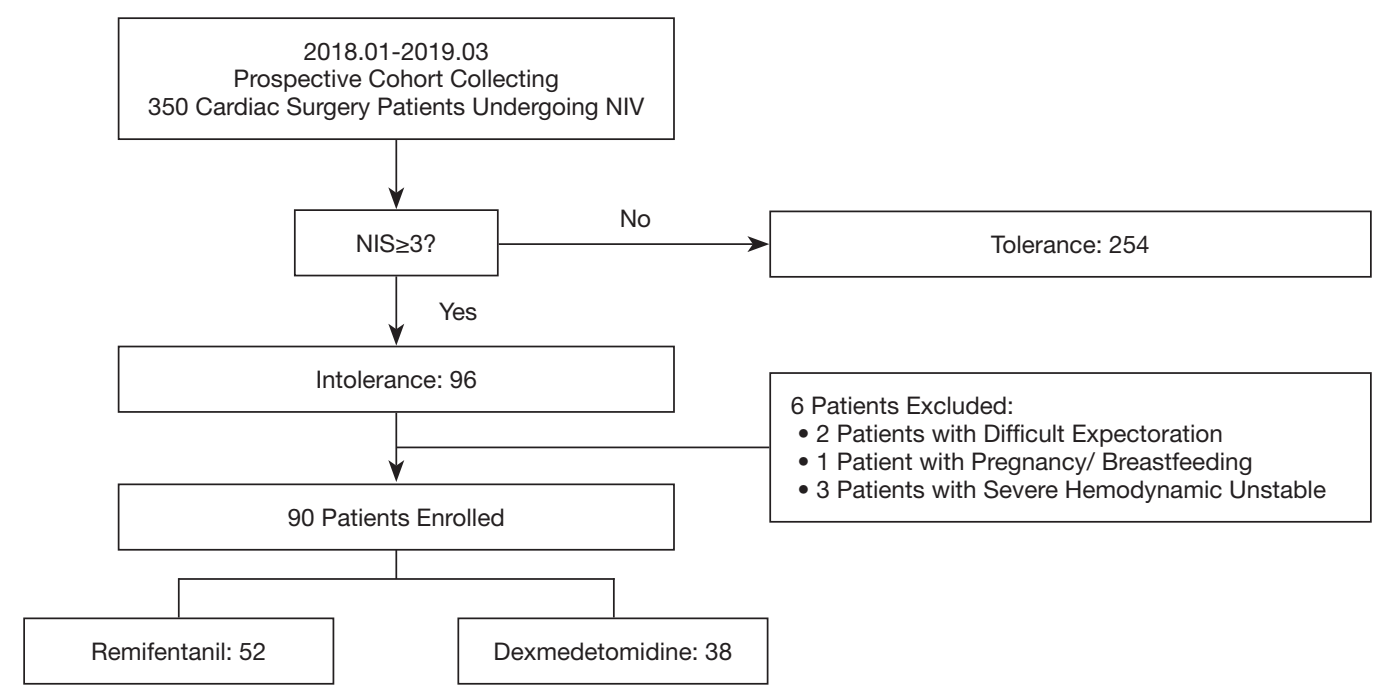

Figure 1 A flow diagram of this study. NIS, noninvasive ventilation intolerance score.

significant. Statistical analysis was performed using R, version 3.6.0 (R Foundation for Statistical Computing, Vienna, Austria)

\section{Results}

\section{Characteristics of enrolled patients}

A total of $350 \mathrm{CS}$ patients received NIV in our CSICU between January 2018 and March 2019. Of these patients, 254 tolerated NIV (NIS $<3$ over a 72-h course) and 96 developed intolerance. After exclusion of patients with difficult expectoration, pregnancy/breastfeeding, or severe hemodynamic instability, a total of 90 patients were enrolled in this study (52 in the REM group and 38 in the DEX group). A flow diagram of the patient selection process was shown in Figure 1.

Preoperative characteristics of all patients were summarized in Table 1. Age, sex, body mass index, diagnosis, comorbidities, ratio of smokers, $\mathrm{N}$ terminal pro $\mathrm{B}$ type natriuretic peptide, and left ventricle ejection fraction were comparable between the two groups. Patient characteristics during surgery and upon ICU admission were shown in Table 2. There were no significant differences between the two groups in terms of type of surgery (six subgroups: valve only, coronary artery bypass graft only, valve and coronary artery bypass graft, great vessel, congenital heart disease, and others), surgical duration, transfusion, European system for cardiac operative risk evaluation (EuroSCORE) or Acute Physiology and Chronic Health Evaluation (APACHE)
II score. As compared with the REM group, the rates of cardiopulmonary bypass $(97.4 \%$ vs. $76.9 \%, \mathrm{P}=0.006)$ and deep hypothermia circulatory arrest $(23.7 \%$ vs. $7.7 \%$, $\mathrm{P}=0.033$ ) were significantly higher in the DEX group.

The baseline characteristics before treatment were shown in Table 3. The primary reason for NIV in both groups was cardiac dysfunction $(91.1 \%)$ with no significant difference between the REM and DEX groups $(92.3 \%$ vs. $89.5 \%, \mathrm{P}=0.641)$. The durations from surgery to extubation (34 vs. $38.5 \mathrm{~h}, \mathrm{P}=0.759$ ), from extubation to NIV (23 vs. $25 \mathrm{~h}, \mathrm{P}=0.728$ ), and from NIV to sedation (11 vs. $12 \mathrm{~min}$, $\mathrm{P}=0.697)$ were comparable between the two groups. In addition, the baseline NIV parameters, including support pressure, $\mathrm{FiO}_{2}$, and tidal volume, were similar between groups. An expiratory positive airway pressure of $5 \mathrm{cmH}_{2} \mathrm{O}$ was applied to all patients. Differences in NIS between the two groups were not significant. Before treatment, the Critical-Care Pain Observation Tool score was 0-2 for all patients. Vital signs (heart rate, RR, systolic blood pressure, diastolic blood pressure, mean blood pressure, and $\mathrm{SpO}_{2}$ ) and blood gas analysis $\left(\mathrm{PH}, \mathrm{PaO}_{2}\right.$, and $\left.\mathrm{PaCO}_{2}\right)$ were also comparable before treatment.

\section{The time-dependent therapeutic effects of two treatments}

The status of the enrolled patients in the two groups over the course of study was shown in Figure 2. And mitigation rates at different time points were shown in Figure 3. As compared to the DEX group, the mitigation rate at 
Table 1 Preoperative characteristics of patients with NIV intolerance

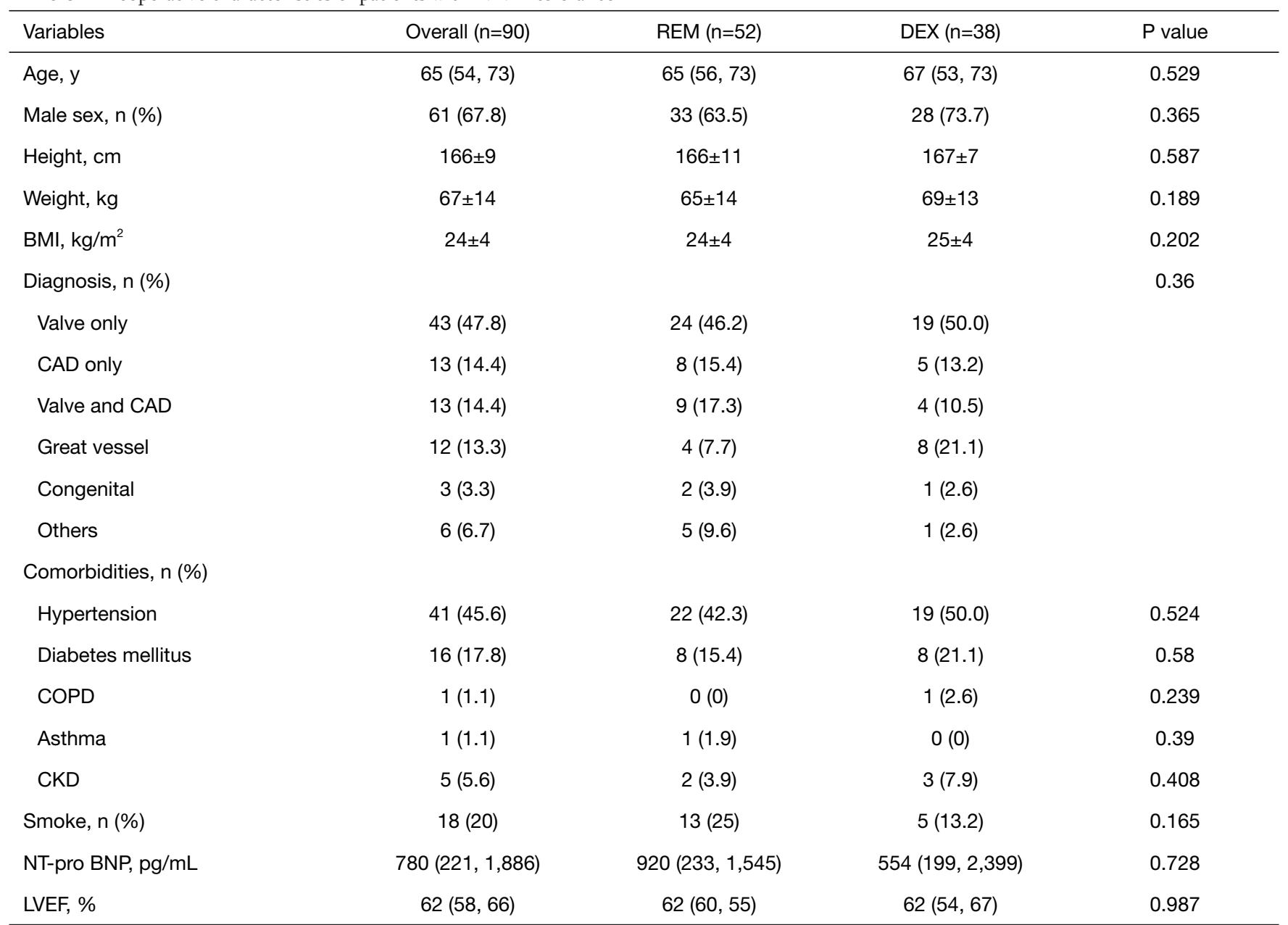

Continuous data are presented as the mean (SD) or median (IQR). Categorical data are presented as counts (\%). BMI, body mass index; CAD, coronary artery disease; COPD, chronic obstructive pulmonary disease; CKD, chronic kidney disease; NT-pro BNT, N terminal pro B type natriuretic peptide; LVEF, left ventricular ejection fraction.

$15 \mathrm{~min}$ and $3 \mathrm{~h}$ was much higher in the REM group (15 min: $83 \%$ vs. $61 \%, \mathrm{P}=0.029 ; 3$ h: $92 \%$ vs. $74 \%$, $\mathrm{P}=0.016)$. The mitigation rate at $1 \mathrm{~h}$ was higher in the REM group too, but with no significant difference $(90 \%$ vs. $76 \%, \mathrm{P}=0.069)$. The mitigation rates evolved along with time and presented a crossover point. Meanwhile, there was no significant difference in the $72-\mathrm{h}$ mean mitigation rates between the DEX and REM groups (81\% vs. $85 \%$, $\mathrm{P}=0.800$ ). When time was taken to account, the generalized estimating equation derived two factors for mitigation rates: DEX [odds ratio $(\mathrm{OR})=0.522 ; 95 \%$ confidence interval $(\mathrm{CI})$ : $0.397-0.687$ ] and time (OR $=0.969$; 95\% CI: 0.965-0.973). The OR of the interaction term between DEX and time was 1.015 (95\% CI: 1.008-1.021), implying that the therapeutic effect of DEX was time cumulative. Besides, there was no significant difference in NIV failure (19.2\% vs. $21.1 \%$, $\mathrm{P}=0.831$ ) between the two groups.

\section{Medications, adverse effects, and clinical outcomes}

The medications administered in this study, as well as any adverse effects and the clinical outcomes were shown in Table 4. The median duration spent in this study of the REM and DEX groups were 13.5 and $12 \mathrm{~h}$, respectively. No patient was deeply sedated (RASS score $\leq 4$ ) in this study. Chest wall rigidity was observed in one patient in the REM group, although spontaneous breathing resumed before $\mathrm{SpO}_{2}$ began to decrease. Vomiting was observed in one patient in the 
Table 2 Intraoperative and postoperative characteristics of patients with NIV intolerance

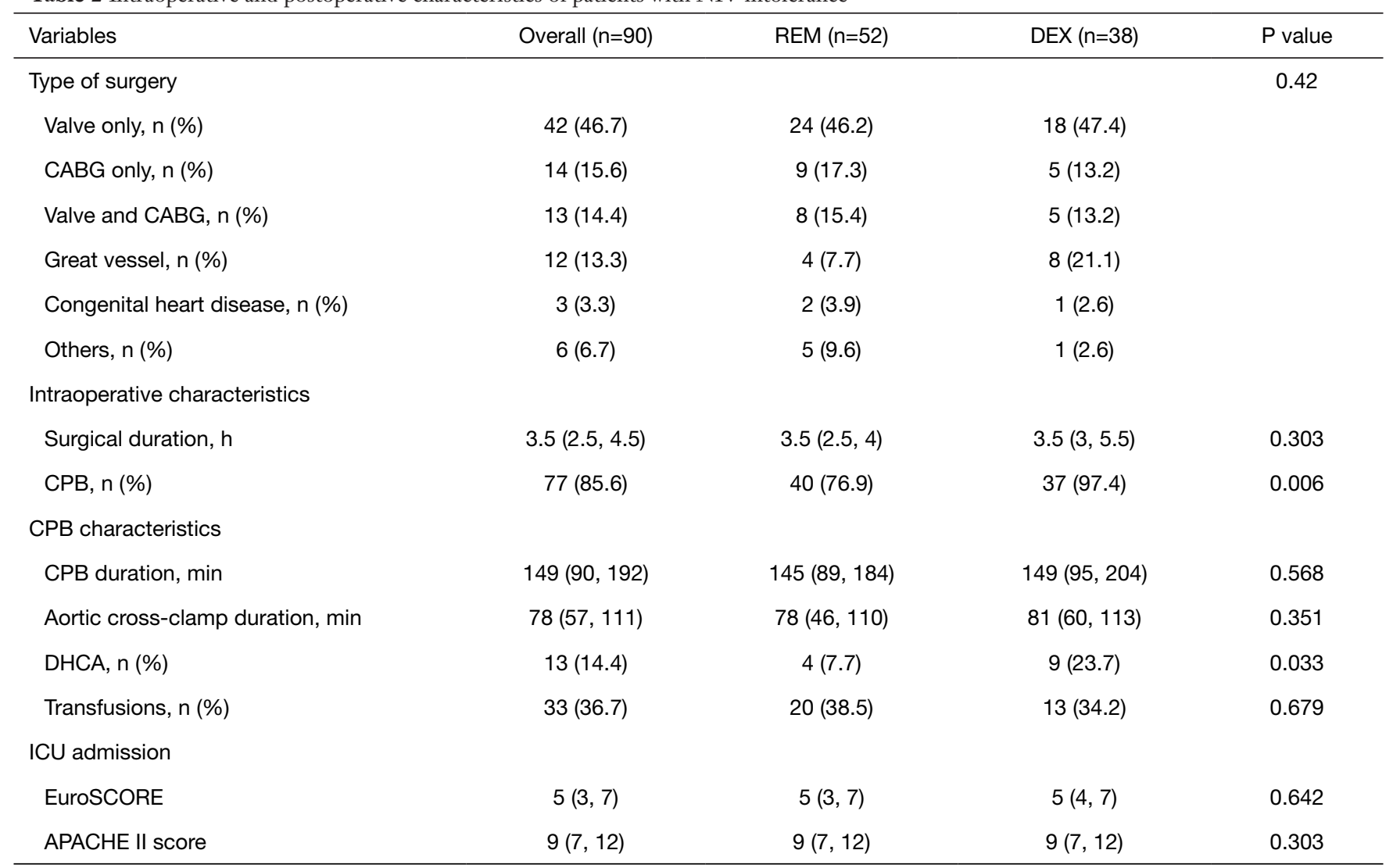

Continuous data are presented as the mean (SD) or median (IQR). Categorical data are presented as counts (\%). CABG, coronary artery bypass grafting; CPB, cardiopulmonary bypass; DHCA, deep hypothermic circulatory arrest; EuroSCORE, European system for cardiac-operative risk evaluation; APACHE, Acute Physiology and Chronic Health Evaluation.

REM group, which was alleviated soon after intramuscular injection of $10 \mathrm{mg}$ of metoclopramide. One patient in the DEX group required reintubation due to severe hemodynamic instability, which was eventually corrected at about $2 \mathrm{~h}$ after discontinuation of DEX. The minimum and maximum infusion dosages of REM were $0.04 \pm 0.01$ and $0.06 \pm 0.02 \mu \mathrm{g} / \mathrm{kg} / \mathrm{min}$, respectively, and those of DEX were $0.42 \pm 0.10$ and $0.60 \pm 0.20 \mu \mathrm{g} / \mathrm{kg} / \mathrm{h}$, respectively. There were no significant differences between the two groups in the use of combined medications (e.g., midazolam and olanzapine). Differences in clinical outcomes, such as tracheostomy (15.4\% vs. $15.8 \%, \mathrm{P}=0.958)$, in-hospital mortality $(11.5 \%$ vs. $10.5 \%, \mathrm{P}=0.880)$, ICU length of stay (LOS) (7 vs. 7 days, $\mathrm{P}=0.802)$ and in-hospital LOS (17 vs. 19 days, $\mathrm{P}=0.589)$ were not significant between the two groups, too. The median duration from treatment to reintubation in the REM and DEX groups were 10 and $15 \mathrm{~h}$, respectively. Mechanical ventilator settings, vital signs, NIV intolerance score, RASS score, and medication dosage at different time points (15 min and 1, 3, 6, 12, 24, 36, 48, 60, and $72 \mathrm{~h}$ ) were shown in Table $S 1$.

\section{Discussion}

In this prospective, cohort study, the mitigation rate was greater in REM group over the first $3 \mathrm{~h}$, however, the 72-h mean mitigation rate was comparable between the two groups of CS patients with moderate to severe NIV intolerance. Difference of NIV failure and other clinical outcomes (i.e., tracheostomy, ICU LOS, in-hospital LOS, and in-hospital mortality) were not significant between the two groups. And adverse effects of both drugs were rare in this study. To the best of our knowledge, this is the first study to evaluate the effects of REM versus DEX in CS patients with moderate to severe NIV intolerance.

In this study, NIV failure was avoided in more than $80 \%$ 
Table 3 Baseline characteristics of patients with NIV intolerance prior to treatment

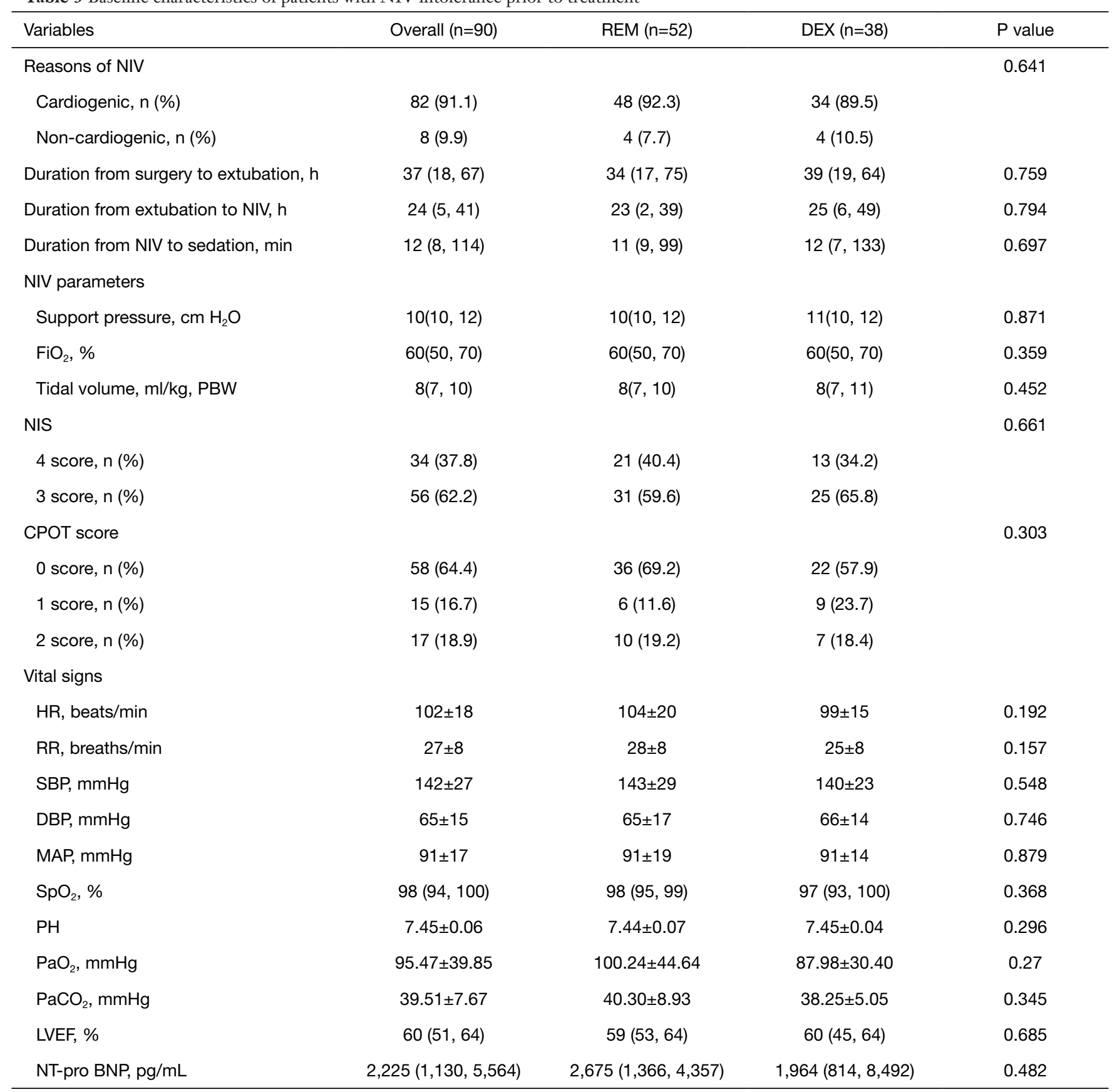

Continuous data are presented as the mean (SD) or median (IQR). Categorical data are presented as counts (\%). NIV, noninvasive ventilation; PBW, predicted body weight; NIS, NIV intolerance score; CPOT, Critical-Care Pain Observation Tool; HR, heart rate; RR, respiratory rate; SBP, systolic blood pressure; DBP, diastolic blood pressure; MAP, mean artery pressure, LVEF, left ventricular ejection fraction; NT-pro BNT, N terminal pro B type natriuretic peptide. 

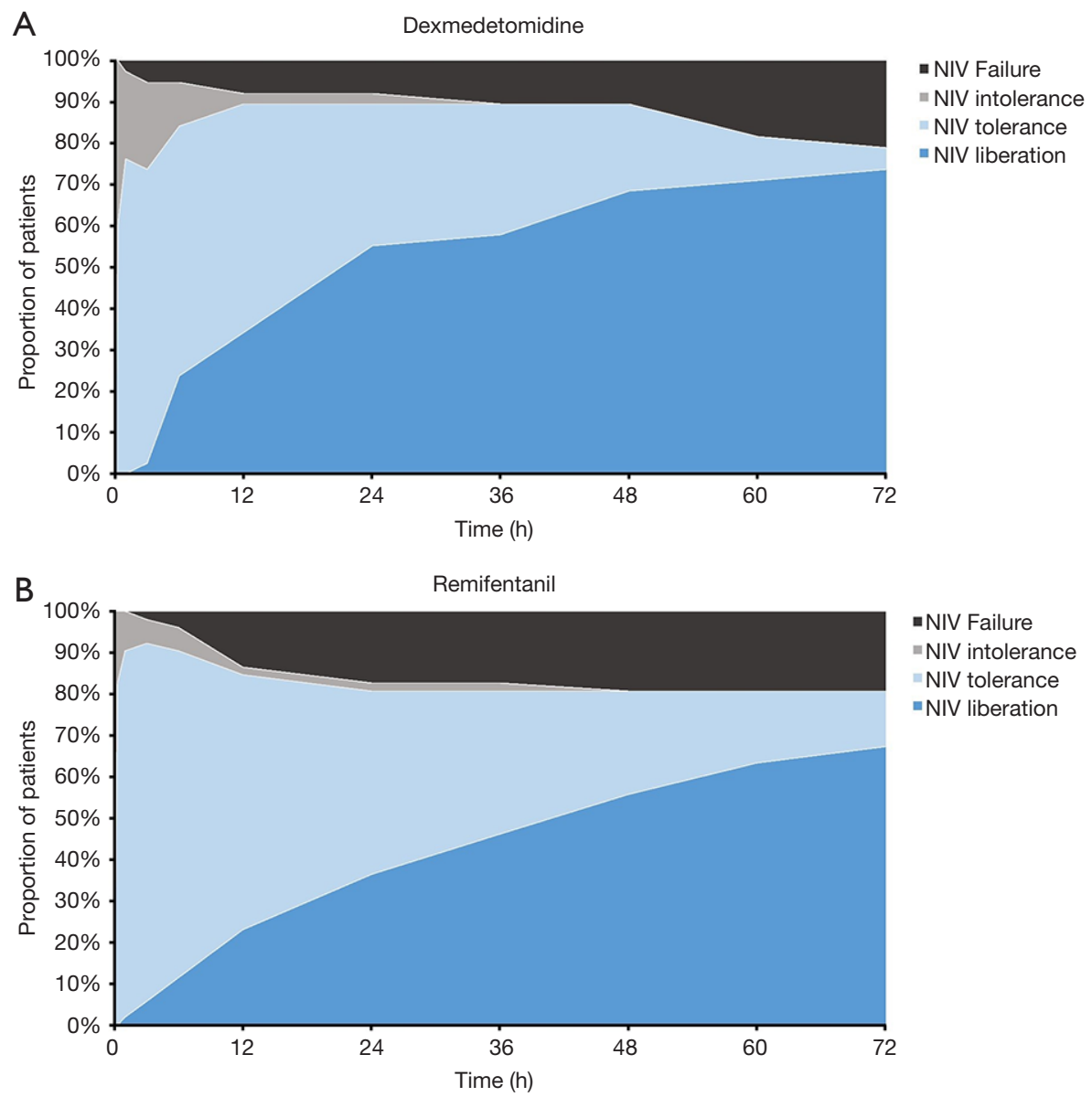

Figure 2 PSA chart for clinical status of CS patients with NIV treated with DEX (A) and REM (B). PSA, percentage stacked area.

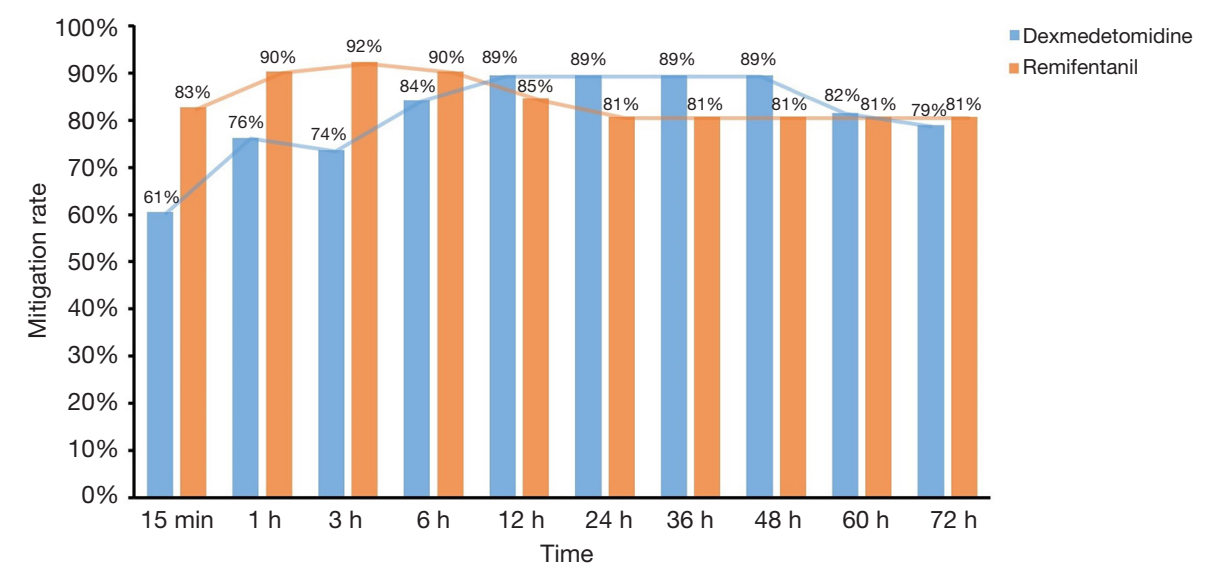

Figure 3 The time-dependent therapeutic effects of two sedative drugs. 
Table 4 Medications, adverse events, and clinical outcomes of patients with NIV intolerance

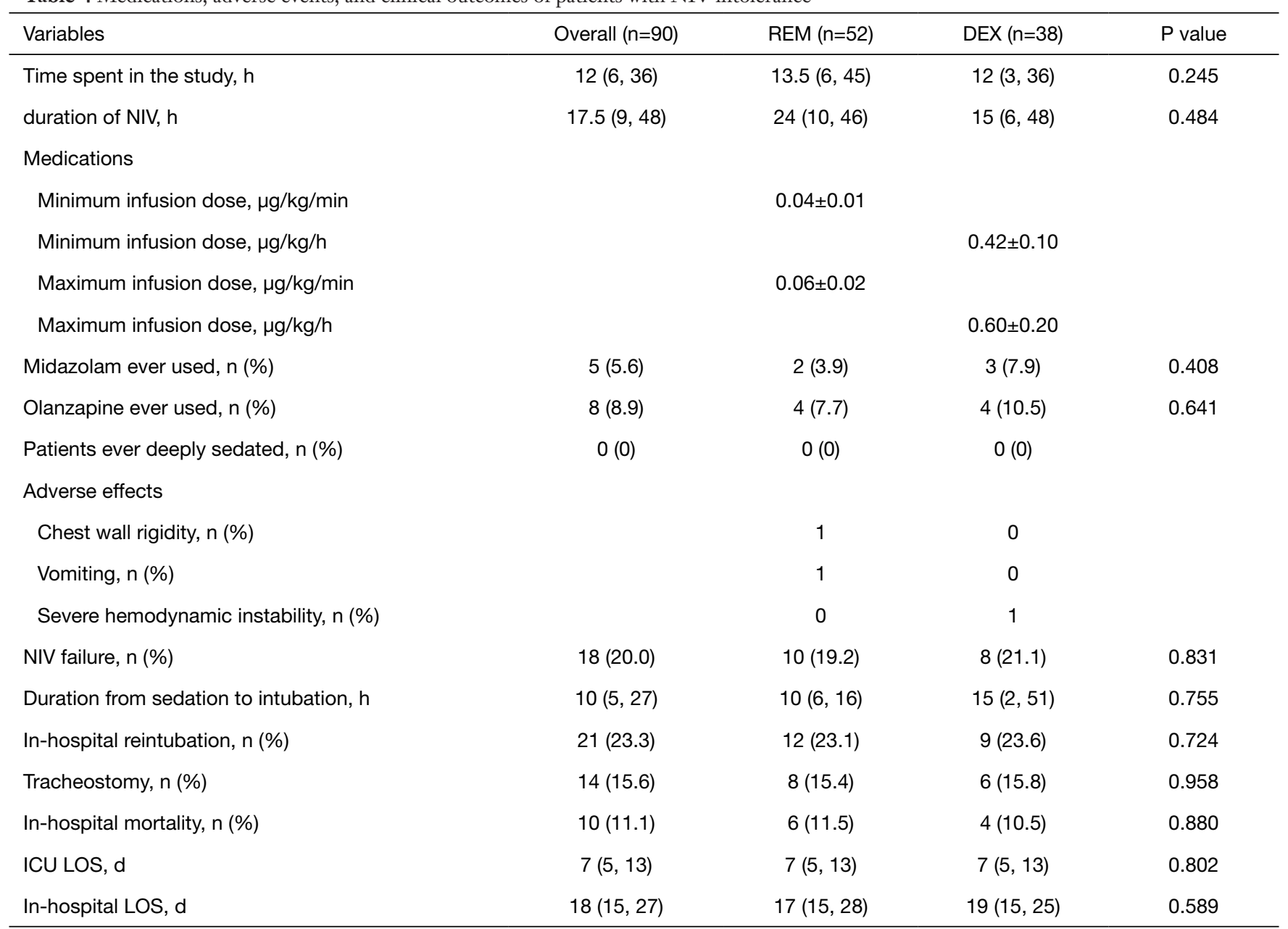

Continuous data are presented as the mean (SD) or median (IQR). Categorical data are presented as counts (\%). NIV, noninvasive ventilation; ICU, intensive care unit; LOS, length of stay.

of the enrolled patients. Although the use of sedation to NIV patients remains controversial $(9,12,31)$, administration of analgesics and sedatives might be beneficial for intolerant patients who are uncooperative before resorting to intubation (31). Also, preliminary studies have shown that REM and DEX were both effective for treatment of NIVintolerance $(10,32,33)$. On the one hand dexmedetomidine was able to treat delirium and guarantee comfort during NIV support, remifentanil on the other hand was able to control pain and reduce respiratory drive during NIV and allow the patient to cope with the ventilator. As compared to the DEX group, the mitigation rate over the first $3 \mathrm{~h}$ was greater in the REM group, which might be contributed to the quick onset of REM (within $1 \mathrm{~min}$ ). In contrast, at a loading dose of $1 \mu \mathrm{g} / \mathrm{kg} / \mathrm{min}$, the onset of DEX was about
10 to $15 \mathrm{~min}$ (24). However, a loading dose of DEX is not recommended by the European Medicines Agency (34). Therefore, no loading dose of either sedative was applied in this study.

The major concern of treatment in patients receiving NIV is the severe side effects of sedatives (31), such as chest wall rigidity, vomiting, and severe hemodynamic instability. Shehabi et al. reported a $16 \%$ decrease in mean systolic blood pressure and a $21 \%$ decrease in heart rate in critically ill patients receiving continuous infusion of DEX $(0.2-0.7 \mu \mathrm{g} / \mathrm{kg} / \mathrm{h}$, without a loading dose) over a period of $24 \mathrm{~h}$ (22). Giorgio et al. demonstrated that analgesics and sedatives must be applied under appropriate monitoring by experienced staff (31). In this study, chest wall rigidity was observed in one patient in the REM group. Notably, 
this is an extremely severe side effect that might require immediate reintubation. However, in this case, spontaneous breathing resumed soon after discontinuation of REM, even before $\mathrm{SpO}_{2}$ began to decrease, so reintubation was avoided, possibly due to the quick offset of the effects of REM, which allowed prompt recovery after discontinuation of the infusion. Severe hemodynamic instability was observed in one patient in the DEX group, which necessitated reintubation because it took about $2 \mathrm{~h}$ for the circulation to stabilize.

The major reason for NIV in this study was cardiac dysfunction, which was characterized by increased work of breathing (35), manifesting as tachypnea with a high respiratory drive. According to the American Thoracic Society guideline (2017), NIV might be used as a ventilatory support for these patients (29). However, studies have shown that a high respiratory drive with strong inspiratory efforts could promote patient-ventilator asynchrony $(36,37)$ and increase oxygen cost of breathing (38), thereby further increasing ventilatory demands and, thus, exacerbating the pre-existing strenuous breathing and tachypnea. Hence, decreased RR might be an indicator of treatment success. In this study, 15 min after the initiation of REM, the mean RR decreased from $28 \pm 8$ to $23 \pm 6$ breaths/min, and further decreased to $20 \pm 6$ breaths/min over a period of $3 \mathrm{~h}$. This was consistent with the findings of previous studies demonstrating REM as a safe and effective sedative for NIV failure due to low tolerance $(10,32)$. Depression of respiratory drive is a widely known adverse effect of opioids. Cavaliere et al. concluded that REM infusion at a dose greater than $0.05 \mu \mathrm{g} / \mathrm{kg} / \mathrm{min}$ could inhibit respiratory drive (39). The significant decrease in RR in the REM group indicated depression of respiratory drive in this study. However, as no patients were deeply sedated and no severe hemodynamic instability occurred in the REM group, titrating the dosage of REM to the extent of depressing respiratory drive was safe under appropriate monitoring by experienced staff.

There were several limitations to this study. First, this was not a randomized study, the treatments were chosen by the bedside intensivist, however, most of the baseline characteristics were well matched between the two groups. Second, because of the limited sample size, it was difficult to arrive at definite conclusions about which one was better. Third, this study was conducted in a single center. The intensivists in our center are familiar with NIV and opioids, and able to deal with problems related to NIV therapy and sedation. As a result, further studies are needed to confirm the results of this study for generalization to other ICUs.

\section{Conclusions}

The results of this study revealed that REM was as effective as DEX for sedation of CS patients with moderate to severe NIV intolerance. Although REM was more effective than DEX over the first $3 \mathrm{~h}$, the cumulative effect was similar between the two treatments.

\section{Acknowledgments}

Funding: This article was supported by grants from the Research Funds of Zhongshan Hospital (2019ZSYXQN34, 2019ZSQN13 and XYYX201922) and the Research Fund of Shanghai Municipal Health Commission (2019ZB0105), Program of Shanghai Academic/Technology Research Leader (20XD1421000) and Natural Science Foundation of Shanghai (20ZR1411100).

\section{Footnote}

Reporting Checklist: The authors have completed the STROBE reporting checklist. Available at http://dx.doi. org/10.21037/jtd-20-1678

Data Sharing Statement: Available at http://dx.doi. org/10.21037/jtd-20-1678

Peer Review File: Available at http://dx.doi.org/10.21037/jtd20-1678

Conflicts of Interest: All authors have completed the ICMJE uniform disclosure form (available at http://dx.doi. org/10.21037/jtd-20-1678). The authors have no conflicts of interest to declare.

Ethical Statement: The authors are accountable for all aspects of the work in ensuring that questions related to the accuracy or integrity of any part of the work are appropriately investigated and resolved. The study was conducted in accordance with the Declaration of Helsinki (as revised in 2013). The study was approved by the Ethical Committee of Zhongshan hospital, Fudan University (NO. B2017-187), informed consent was acquired from each patient's relatives.

Open Access Statement: This is an Open Access article 
distributed in accordance with the Creative Commons Attribution-NonCommercial-NoDerivs 4.0 International License (CC BY-NC-ND 4.0), which permits the noncommercial replication and distribution of the article with the strict proviso that no changes or edits are made and the original work is properly cited (including links to both the formal publication through the relevant DOI and the license). See: https://creativecommons.org/licenses/by-nc-nd/4.0/.

\section{References}

1. Ampatzidou F, Boutou AK, Karagounis L, et al. Noninvasive Ventilation to Treat Respiratory Failure After Cardiac Surgery: Predictors of Application and Outcome. Respir Care 2019;64:1123-31.

2. Liu Y, An Z, Chen J, et al. Risk factors for noninvasive ventilation failure in patients with post-extubation acute respiratory failure after cardiac surgery. J Thorac Dis 2018;10:3319-28.

3. Pieczkoski SM, Margarites AGF, Sbruzzi G. Noninvasive Ventilation During Immediate Postoperative Period in Cardiac Surgery Patients: Systematic Review and MetaAnalysis. Braz J Cardiovasc Surg 2017;32:301-11.

4. Garcia-Delgado M, Navarrete I, Garcia-Palma MJ, et al. Postoperative respiratory failure after cardiac surgery: use of noninvasive ventilation. J Cardiothorac Vasc Anesth 2012;26:443-7.

5. Bello G, De Pascale G, Antonelli M. Noninvasive ventilation: practical advice. Curr Opin Crit Care 2013;19:1-8.

6. Scott JB. Ventilators for Noninvasive Ventilation in Adult Acute Care. Respir Care 2019;64:712-22.

7. Hilbert G, Clouzeau B, Nam Bui H, et al. Sedation during non-invasive ventilation. Minerva Anestesiol 2012;78:842-6.

8. Ni YN, Wang T, Yu H, et al. The effect of sedation and/ or analgesia as rescue treatment during noninvasive positive pressure ventilation in the patients with Interface intolerance after Extubation. BMC Pulm Med 2017;17:125.

9. Hilbert G, Navalesi P, Girault C. Is sedation safe and beneficial in patients receiving NIV? Yes. Intensive Care Med 2015;41:1688-91.

10. Constantin JM, Schneider E, Cayot-Constantin S, et al. Remifentanil-based sedation to treat noninvasive ventilation failure: a preliminary study. Intensive Care Med 2007;33:82-7.

11. Piastra M, Pizza A, Gaddi S, et al. Dexmedetomidine is effective and safe during NIV in infants and young children with acute respiratory failure. BMC Pediatr 2018;18:282.

12. Longrois D, Conti G, Mantz J, et al. Sedation in noninvasive ventilation: do we know what to do (and why)? Multidiscip Respir Med 2014;9:56.

13. Wijeysundera DN, Bender JS, Beattie WS. Alpha-2 adrenergic agonists for the prevention of cardiac complications among patients undergoing surgery. Cochrane Database Syst Rev 2009:CD004126.

14. Gertler R, Brown HC, Mitchell DH, et al. Dexmedetomidine: a novel sedative-analgesic agent. Proc (Bayl Univ Med Cent) 2001;14:13-21.

15. Pasero D, Sangalli F, Baiocchi M, et al. Experienced Use of Dexmedetomidine in the Intensive Care Unit: A Report of a Structured Consensus. Turk J Anaesthesiol Reanim 2018;46:176-83.

16. Flukiger J, Hollinger A, Speich B, et al. Dexmedetomidine in prevention and treatment of postoperative and intensive care unit delirium: a systematic review and meta-analysis. Ann Intensive Care 2018;8:92.

17. Dalfino L, Brienza N, Bruno F. Patient-targeted light sedation in the Intensive Care Unit: are we ready for precision medicine with dexmedetomidine? Minerva Anestesiol 2018;84:661-3.

18. Shi C, Jin J, Qiao L, et al. Effect of perioperative administration of dexmedetomidine on delirium after cardiac surgery in elderly patients: a double-blinded, multi-center, randomized study. Clin Interv Aging 2019;14:571-5.

19. Chuich T, Cropsey CL, Shi Y, et al. Perioperative Sedation in Mechanically Ventilated Cardiac Surgery Patients With Dexmedetomidine-Based Versus Propofol-Based Regimens. Ann Pharmacother 2019;53:5-12.

20. Liu H, Ji F, Peng K, et al. Sedation After Cardiac Surgery: Is One Drug Better Than Another? Anesth Analg 2017;124:1061-70.

21. Ebert TJ, Hall JE, Barney JA, et al. The effects of increasing plasma concentrations of dexmedetomidine in humans. Anesthesiology 2000;93:382-94.

22. Shehabi $Y$, Ruettimann $U$, Adamson $H$, et al. Dexmedetomidine infusion for more than 24 hours in critically ill patients: sedative and cardiovascular effects. Intensive Care Med 2004;30:2188-96.

23. Rawal H, Patel BM. Opioids in Cardiovascular Disease: Therapeutic Options. J Cardiovasc Pharmacol Ther 2018;23:279-91.

24. Jo YY, Kwak HJ. Sedation Strategies for Procedures 
Outside the Operating Room. Yonsei Med J 2019;60:491-9.

25. Conti G, Costa R, Pellegrini A, et al. Analgesia in PACU: intravenous opioids. Curr Drug Targets 2005;6:767-71.

26. Hoke JF, Shlugman D, Dershwitz M, et al. Pharmacokinetics and pharmacodynamics of remifentanil in persons with renal failure compared with healthy volunteers. Anesthesiology 1997;87:533-41.

27. Carlucci A, Pisani L, Ceriana P, et al. Patient-ventilator asynchronies: may the respiratory mechanics play a role? Crit Care 2013;17:R54.

28. Devlin JW, Al-Qadheeb NS, Chi A, et al. Efficacy and safety of early dexmedetomidine during noninvasive ventilation for patients with acute respiratory failure: a randomized, double-blind, placebo-controlled pilot study. Chest 2014;145:1204-12.

29. Rochwerg B, Brochard L, Elliott MW, et al. Official ERS/ ATS clinical practice guidelines: noninvasive ventilation for acute respiratory failure. Eur Respir J 2017;50.

30. Sessler CN, Gosnell MS, Grap MJ, et al. The Richmond Agitation-Sedation Scale: validity and reliability in adult intensive care unit patients. Am J Respir Crit Care Med 2002;166:1338-44.

31. Conti G, Hill NS, Nava S. Is sedation safe and beneficial in patients receiving NIV? No. Intensive Care Med 2015;41:1692-5.

Cite this article as: Hao GW, Luo JC, Xue Y, Ma GG, Su Y, Hou JY, Yu SJ, Liu K, Zheng JL, Tu GW, Luo Z. Remifentanil versus dexmedetomidine for treatment of cardiac surgery patients with moderate to severe noninvasive ventilation intolerance (REDNIVIN): a prospective, cohort study. J Thorac Dis 2020;12(10):5857-5868. doi: 10.21037/jtd-20-1678
32. Rocco M, Conti G, Alessandri E, et al. Rescue treatment for noninvasive ventilation failure due to interface intolerance with remifentanil analgosedation: a pilot study. Intensive Care Med 2010;36:2060-5.

33. Akada S, Takeda S, Yoshida Y, et al. The efficacy of dexmedetomidine in patients with noninvasive ventilation: a preliminary study. Anesth Analg 2008;107:167-70.

34. Keating GM. Dexmedetomidine: A Review of Its Use for Sedation in the Intensive Care Setting. Drugs 2015;75:1119-30.

35. Bello G, De Santis P, Antonelli M. Non-invasive ventilation in cardiogenic pulmonary edema. Ann Transl Med 2018;6:355.

36. Tobin MJ, Laghi F, Jubran A. Ventilatory failure, ventilator support, and ventilator weaning. Compr Physiol 2012;2:2871-921.

37. Kondili E, Prinianakis G, Georgopoulos D. Patientventilator interaction. Br J Anaesth 2003;91:106-19.

38. Viale JP, Annat GJ, Bouffard YM, et al. Oxygen cost of breathing in postoperative patients. Pressure support ventilation vs continuous positive airway pressure. Chest 1988;93:506-9.

39. Cavaliere F, Antonelli M, Arcangeli A, et al. A lowdose remifentanil infusion is well tolerated for sedation in mechanically ventilated, critically-ill patients. Can J Anaesth 2002;49:1088-94. 
Table S1 NIV-associated data over the course of the study

\begin{tabular}{|c|c|c|c|c|c|c|c|c|c|c|c|}
\hline Variables & Groups & $15 \mathrm{~min}$ & $1 \mathrm{~h}$ & $3 \mathrm{~h}$ & $6 \mathrm{~h}$ & $12 \mathrm{~h}$ & $24 \mathrm{~h}$ & $36 \mathrm{~h}$ & $48 \mathrm{~h}$ & $60 \mathrm{~h}$ & $72 \mathrm{~h}$ \\
\hline \multicolumn{12}{|l|}{ MV settings } \\
\hline \multirow[t]{2}{*}{ Support pressure, $\mathrm{cmH}_{2} \mathrm{O}$} & Remifentanil & $10(10,12)$ & $12(10,12)$ & $12(10,12)$ & $12(10,12)$ & $12(10,12)$ & $12(10,12)$ & $12(10,12)$ & $12(10,12)$ & ) $12(10,12)$ & $12(11,14)$ \\
\hline & Dexmedetomidine & $12(10,12)$ & $12(10,12)$ & $10(10,12)$ & $12(10,12)$ & $12(10,12)$ & $12(10,12)$ & $12(10,12)$ & $11(10,12)$ & $12(11,14)$ & $13.5(11,14)$ \\
\hline \multirow[t]{2}{*}{$\mathrm{FiO}_{2}, \%$} & Remifentanil & $60(50,70)$ & $60(50,70)$ & $60(50,70)$ & $60(50,70)$ & $60(50,70)$ & $60(50,70)$ & $50(50,60)$ & $50(50,60)$ & $60(45,60)$ & $60(50,70)$ \\
\hline & Dexmedetomidine & $60(50,70)$ & $50(50,70)$ & $50(50,70)$ & $50(50,70)$ & $50(50,77.5)$ & $50(50,75)$ & $50(50,70)$ & $50(50,50)$ & $50(42.5,50)$ & ) $50(50,50)$ \\
\hline \multirow[t]{2}{*}{ Tidal volume, mL/kg, PBW } & Remifentanil & $8(7,10)$ & $8(7,10)$ & $9(7,10)$ & $9(7,10)$ & $9(7,10)$ & $8(7,10)$ & $9(7,9)$ & $8(7,10)$ & $9(8,9)$ & $9(8,10)$ \\
\hline & Dexmedetomidine & $8(7,11)$ & $8(7,11)$ & $9(7,11)$ & $9(8,11)$ & $9(8,10)$ & $8(8,10)$ & $9(8,11)$ & $9(8,12)$ & $9(8,12)$ & $9(8,10)$ \\
\hline \multicolumn{12}{|l|}{ Vital signs } \\
\hline \multirow[t]{2}{*}{$\mathrm{HR}$, beats/min } & Remifentanil & $101 \pm 19$ & $100 \pm 20$ & $98 \pm 20$ & $98 \pm 20$ & $96 \pm 19$ & $97 \pm 21$ & $93 \pm 16$ & $100 \pm 23$ & $88 \pm 15$ & $89 \pm 18$ \\
\hline & Dexmedetomidine & $97 \pm 17$ & $92 \pm 20$ & $91 \pm 17$ & $88 \pm 18$ & $83 \pm 15$ & $81 \pm 14$ & $86 \pm 20$ & $84 \pm 16$ & $80 \pm 19$ & $77 \pm 20$ \\
\hline \multirow[t]{2}{*}{$\mathrm{SBP}, \mathrm{mmHg}$} & Remifentanil & $135 \pm 23$ & $132 \pm 22$ & $128 \pm 20$ & $132 \pm 20$ & $131 \pm 23$ & $130 \pm 17$ & $128 \pm 19$ & $128 \pm 20$ & $128 \pm 16$ & $124 \pm 11$ \\
\hline & Dexmedetomidine & $131 \pm 23$ & $126 \pm 22$ & $123 \pm 19$ & $114 \pm 18$ & $123 \pm 15$ & $124 \pm 15$ & $121 \pm 13$ & $131 \pm 18$ & $127 \pm 15$ & $126 \pm 25$ \\
\hline \multirow[t]{2}{*}{$\mathrm{DBP}, \mathrm{mmHg}$} & Remifentanil & $64 \pm 12$ & $63 \pm 12$ & $59 \pm 11$ & $61 \pm 10$ & $63 \pm 12$ & $63 \pm 14$ & $64 \pm 8$ & $61 \pm 11$ & $64 \pm 9$ & $68 \pm 7$ \\
\hline & Dexmedetomidine & $64 \pm 15$ & $61 \pm 12$ & $61 \pm 13$ & $59 \pm 12$ & $60 \pm 12$ & $61 \pm 9$ & $59 \pm 9$ & $63 \pm 11$ & $61 \pm 14$ & $66 \pm 12$ \\
\hline \multirow[t]{2}{*}{ MAP, mmHg } & Remifentanil & $88 \pm 13$ & $86 \pm 12$ & $82 \pm 11$ & $84 \pm 10$ & $86 \pm 12$ & $85 \pm 12$ & $85 \pm 9$ & $61 \pm 11$ & $85 \pm 8$ & $87 \pm 6$ \\
\hline & Dexmedetomidine & $86 \pm 16$ & $83 \pm 12$ & $81 \pm 13$ & $78 \pm 12$ & $81 \pm 10$ & $82 \pm 9$ & $80 \pm 9$ & $63 \pm 11$ & $83 \pm 12$ & $86 \pm 14$ \\
\hline \multirow[t]{2}{*}{$\mathrm{SPO}_{2}, \%$} & Remifentanil & $97 \pm 3$ & $98 \pm 2$ & $98 \pm 2$ & $98 \pm 2$ & $98 \pm 2$ & $99 \pm 1$ & $99 \pm 1$ & $99 \pm 1$ & $99 \pm 1$ & $99 \pm 1$ \\
\hline & Dexmedetomidine & $97 \pm 3$ & $98 \pm 3$ & $98 \pm 2$ & $99 \pm 2$ & $99 \pm 2$ & $99 \pm 1$ & $99 \pm 1$ & $99 \pm 1$ & $99 \pm 1$ & $99 \pm 1$ \\
\hline \multirow[t]{2}{*}{$\mathrm{RR}$, breaths/min } & Remifentanil & $23 \pm 6$ & $22 \pm 5$ & $20 \pm 6$ & $20 \pm 6$ & $20 \pm 5$ & $21 \pm 5$ & $22 \pm 7$ & $20 \pm 6$ & $21 \pm 6$ & $22 \pm 6$ \\
\hline & Dexmedetomidine & $24 \pm 7$ & $23 \pm 6$ & $22 \pm 5$ & $21 \pm 6$ & $21 \pm 5$ & $22 \pm 6$ & $22 \pm 5$ & $21 \pm 5$ & $22 \pm 3$ & $23 \pm 5$ \\
\hline \multirow[t]{2}{*}{ NIS } & Remifentanil & $2(1,2)$ & $1(1,2)$ & $1(1,2)$ & $1(1,2)$ & $1(1,2)$ & $1(1,1.75)$ & $1(1,1)$ & $1(1,1)$ & $1(1,1.5)$ & $1(1,1)$ \\
\hline & Dexmedetomidine & $2(1,3)$ & $2(1,2)$ & $2(1,2)$ & $1(1,2)$ & $1(1,2)$ & $1(1,2)$ & $1(1,1.75)$ & $1(1,2)$ & $1(1,1)$ & $1(1,1)$ \\
\hline \multirow[t]{2}{*}{ RASS score } & Remifentanil & $1(0,1)$ & $0(0,0)$ & $0(0,0)$ & $0(0,0)$ & $0(0,0)$ & $0(0,0)$ & $0(0,0)$ & $0(0,0)$ & $0(-0.5,0)$ & $0(0,0)$ \\
\hline & Dexmedetomidine & $1(0,2)$ & $0(0,1)$ & $0(0,0)$ & $0(0,0)$ & $0(0,0)$ & $0(0,0)$ & $0(0,0)$ & $0(0,0)$ & $0(0,0)$ & $0(0,0)$ \\
\hline \multicolumn{12}{|l|}{ Dose of medication } \\
\hline$\mu \mathrm{g} / \mathrm{kg} / \mathrm{min}$ & Remifentanil & $0.06 \pm 0.02$ & $0.06 \pm 0.02$ & $0.06 \pm 0.02$ & $0.06 \pm 0.02$ & $0.05 \pm 0.02$ & $0.06 \pm 0.02$ & $0.06 \pm 0.02$ & $0.06 \pm 0.03$ & $0.06 \pm 0.03$ & $0.05 \pm 0.03$ \\
\hline$\mu g / \mathrm{kg} / \mathrm{h}$ & Dexmedetomidine & $0.51 \pm 0.15$ & $0.54 \pm 0.17$ & $0.57 \pm 0.19$ & $0.57 \pm 0.22$ & $0.54 \pm 0.19$ & $0.54 \pm 0.18$ & $0.52 \pm 0.18$ & $0.54 \pm 0.18$ & $0.48 \pm 0.15$ & $0.53 \pm 0.12$ \\
\hline \multirow[t]{2}{*}{ Number of subjects } & Remifentanil & 52 & 51 & 48 & 44 & 33 & 24 & 19 & 13 & 9 & 7 \\
\hline & Dexmedetomidine & 38 & 37 & 35 & 27 & 22 & 14 & 12 & 8 & 4 & 2 \\
\hline
\end{tabular}

Continuous data are presented as the mean (SD) or median (IQR). Categorical data are presented as counts (\%). MV, mechanical ventilation; PBW, predicted body weight; HR, heart rate; SBP, systolic blood pressure; DBP, diastolic blood pressure; MAP, mean artery pressure; RR, respiratory rate; NIS, NIV intolerance score; RASS, Richmond Agitation and Sedation Scale. 